\title{
Short Term Results of the Cadence Total Ankle Prosthesis: A Dutch Non-Designer Case Series
}

\author{
Brylka EP, $M D^{1^{*}}$, Sierevelt IN, MSc ${ }^{1}$, Vergroesen $D A, M D^{2}$ and Nolte, $P A, M D, P h D^{1,2}$ \\ ${ }^{1}$ Wetenschapsbureau Orthopedie, Spaarne Gasthuis Academie, Spaarnepoort 1, Netherlands \\ ${ }^{2}$ Department of Orthopedic Surgery, Spaarne Gasthuis, Spaarnepoort 1, Netherlands
}

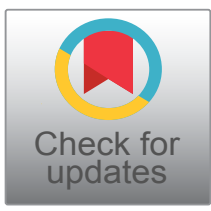

*Corresponding author: Esther P Brylka, Wetenschapsbureau Orthopedie, Spaarne Gasthuis Academie, Spaarnepoort 1, 2134 TM Hoofddorp, Netherlands, Tel: +31-(023)-224-2322

\begin{abstract}
Introduction: Design developments improved outcomes of total ankle replacement (TAR), but the ankle remains difficult to replace with a prosthesis. The aim of this study is to evaluate short-term results of the Cadence Total Ankle System.

Method: Eleven TARs were retrospectively evaluated for intraoperative complications, short-term postoperative complications, clinical outcomes and radiological outcomes.

Results: Nine intraoperative complications occurred in 7 patients and eight short-term post-operative complications occurred in 5 patients. In total $54.5 \%$ of the patients were very satisfied with their TAR with preservation of range of motion (ROM) and clinical and radiological alignment. The pain in the first few postoperative days was mild.

Conclusion: This non-designer case series with our first 11 Cadence TARs shows a high complication rate, which could be caused by factors such as learning curve. However, clinical outcomes are encouraging.
\end{abstract}

\section{Keywords}

Total ankle replacement, Cadence total ankle system, Complications, Radiological alignment

\section{Introduction}

Total ankle replacement (TAR) is one of the surgical treatment options for end-stage ankle osteoarthritis and is gaining popularity since design developments provides improved results. However, despite design developments TAR survivorship is still low compared to total hip and total knee replacement with ten-year survivor rate ranging from $71 \%$ to $94 \%[1-4]$. This may be caused by several factors including the ankle joint being difficult to mimic in a prosthesis due to movement in three planes, the constant moving rotational axis in the talus during dorsiflexion-plantarflexion movement, and tibia bone strength rapidly decreasing below the surface $[5,6]$. Also, the population undergoing TAR is relatively young and ankle osteoarthritis is mostly of secondary origin (i.e. posttraumatic) [3-6].

Furthermore, preoperative coronal plane deformities, common in lateral ligament instability and posttraumatic osteoarthritis, can be challenging to correct. Correction of these deformities is important since it influences the prosthesis survivorship. It can be corrected with techniques such as hindfoot arthrodesis, medial malleolar osteotomy or soft tissue balancing $[7,8]$.

Additionally, TAR is a challenging procedure with a steep learning curve which influences survivorship and complication rates [3,9-12]. Complications associated with TAR are intraoperative malleolus fractures, tendon or nerve lacerations, heterotopic ossification, delayed wound healing, infection, and aseptic loosening [3,4,920].

There are still additional developments in TAR designs. The Cadence Total Ankle System (Integra LifeSciences, Plainsboro, $\mathrm{NJ}$ ) is a relative new ankle prosthesis introduced in 2016 [21]. To our knowledge, there are no published outcomes of the Cadence ankle prosthesis yet. Our hospital is the first in the Netherlands to use the Cadence prosthesis. Therefore, the aim of this study is to evaluate the short-term outcome of the

Citation: Brylka EP, Sierevelt IN, Vergroesen DA, Nolte PA (2020) Short Term Results of the Cadence Total Ankle Prosthesis: A Dutch Non-Designer Case Series. Int J Foot Ankle 4:049. doi.org/10.23937/26433885/1710049

Accepted: September 28, 2020; Published: September 30, 2020

Copyright: (c) 2020 Brylka EP, et al. This is an open-access article distributed under the terms of the Creative Commons Attribution License, which permits unrestricted use, distribution, and reproduction in any medium, provided the original author and source are credited. 
Cadence Total Ankle System in terms of complications, clinical and radiological outcomes.

\section{Methods}

All 11 patients receiving a TAR procedure, mostly due to primary end-stage ankle osteoarthritis, utilizing the Cadence Total Ankle System between October 2017 and April 2019 in a single Dutch orthopaedic surgery department were included for the retrospective analysis. Mean age at surgery was 68.7 years (Table 1 ). Ten patients had 14 different procedures previous to TAR surgery, mostly triple arthrodesis for correction of varus $(n=3)$ or valgus $(n=6)$ ankle malalignment. The mean

Table 1: Patients characteristics $(n=11)$.

\begin{tabular}{|c|c|}
\hline Age at surgery (years), mean (SD) & $68.7(5.4)$ \\
\hline \multicolumn{2}{|l|}{ Gender, n (\%) } \\
\hline Male & $8(72.7)$ \\
\hline Female & $3(27.3)$ \\
\hline Body Mass Index (BMI) $\left(\mathrm{kg} / \mathrm{m}^{2}\right)$, mean (SD) & $32.1(5.6)$ \\
\hline \multicolumn{2}{|l|}{$\begin{array}{l}\text { American Society of Anaesthesiologists } \\
\text { (ASA) classification, } n(\%)\end{array}$} \\
\hline 1 & $1(9.1)$ \\
\hline 2 & $7(63.6)$ \\
\hline 3 & $3(27.3)$ \\
\hline \multicolumn{2}{|l|}{ Diagnosis, $n$ (\%) } \\
\hline Primary osteoarthrosis & $7(63.6)$ \\
\hline Secondary osteoarthrosis & $1(9.1)$ \\
\hline Post-traumatic osteoarthrosis & $3(27.3)$ \\
\hline \multicolumn{2}{|l|}{$\begin{array}{l}\text { Previous ankle surgery (on side of TAR), } \\
\text { n (\%) }\end{array}$} \\
\hline Triple arthrodesis & $10(90.9)$ \\
\hline Ankle fracture treatment & $1(9.1 \%)$ \\
\hline Dwyer osteotomy & $1(7.1 \%)$ \\
\hline Arthroscopy & $1(7.1 \%)$ \\
\hline \multicolumn{2}{|l|}{ Operative side, n (\%) } \\
\hline Left & $7(63.6)$ \\
\hline Right & $4(36.4)$ \\
\hline Follow-up (months), mean (SD) & $10.8(4.2)$ \\
\hline
\end{tabular}

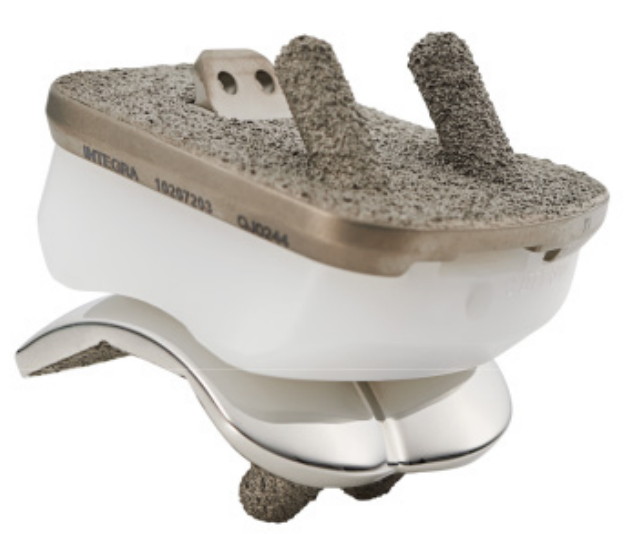

Figure 1: Cadence total ankle system. follow-up was 10.8 months (Table 1 ). Internal review board approval was obtained (ACLU \# 2019.0032).

The Cadence Total Ankle System (Figure 1) is a fixed-bearing prosthesis with left and right specific components. The prosthesis is suitable for both primary and revision TAR and can be performed either cemented or cementless. The tibial component consists of titanium alloy and the talus component of cobalt chrome alloy. The insert consists of highly cross-linked ultra-high molecular weight polyethylene (UHMWPE) and comes in three shapes: Neutral, anterior-biased and posterior-biased. The wide sizing range should improve adaptation to individual patient anatomy [22].

All procedures were cementless and were performed in accordance to manufacturer [22] by two surgeons (D.A.V., P.A.N.) with previous experience in TAR surgery. All additional procedures during TAR surgery, reoperations other than revision and revision procedures were registered. Revision was defined as replacement of any component of the implant, including the insert, or removal of the prosthesis and conversion to arthrodesis. Postoperative care consisted of a non-weight bearing short leg cast for two weeks followed by a weight bearing short leg cast for four to six weeks. Follow-up appointments took place at two and six weeks, three and six months and one year.

Intraoperative bone fractures and nerve or tendon laceration were scored as intraoperative complications and thromboembolism, delayed wound healing, infection and heterotopic ossification ( $\mathrm{HO}$ ) as short-term postoperative complications. Delayed wound healing was defined as a wound not closed at the two weeks post-operative appointment and was considered minor if non-operative treatment was necessary and major if surgical treatment was indicated. Infection was considered as superficial if oral antibiotic treatment was necessary, and as deep if intravenous antibiotic therapy and/or surgical treatment was necessary. $\mathrm{HO}$ was scored on post-operative radiographs in anterior-posterior (AP) and lateral view and was defined as any new osseous formation in either the medial, lateral, anterior or posterior gutter of the ankle [15].

Clinical outcomes were pain, ROM, clinical ankle alignment and patient satisfaction. Pain was scored on an 11-point pain Numeric Rating Scale (NRS) in which 0 represents no pain and 10 represents the worst pain imaginable and was obtained verbally in the postoperative period. ROM and ankle alignment were clinically determined during physical examination preoperatively and 3-6 months postoperatively. Patient satisfaction was collected from patient records and was scored as three levels: Very satisfied, moderately satisfied or unsatisfied.

Radiological outcomes were analysed using preoperative and postoperative radiographs in AP and lateral 


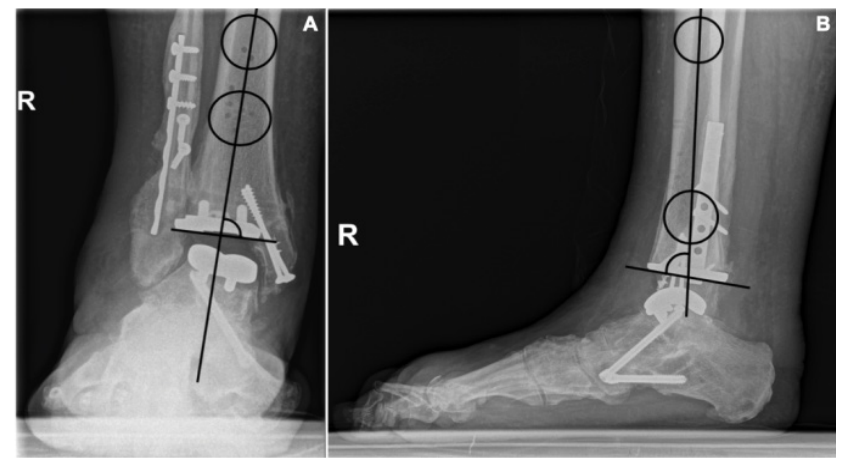

Figure 2: Tibial alignment measured with the angle between the mechanical axis of the tibia and, in the postoperative situation, the tibia component: (A) The medial distal tibial angle (MDTA) and; (B) the anterior distal tibial angle (ADTA).

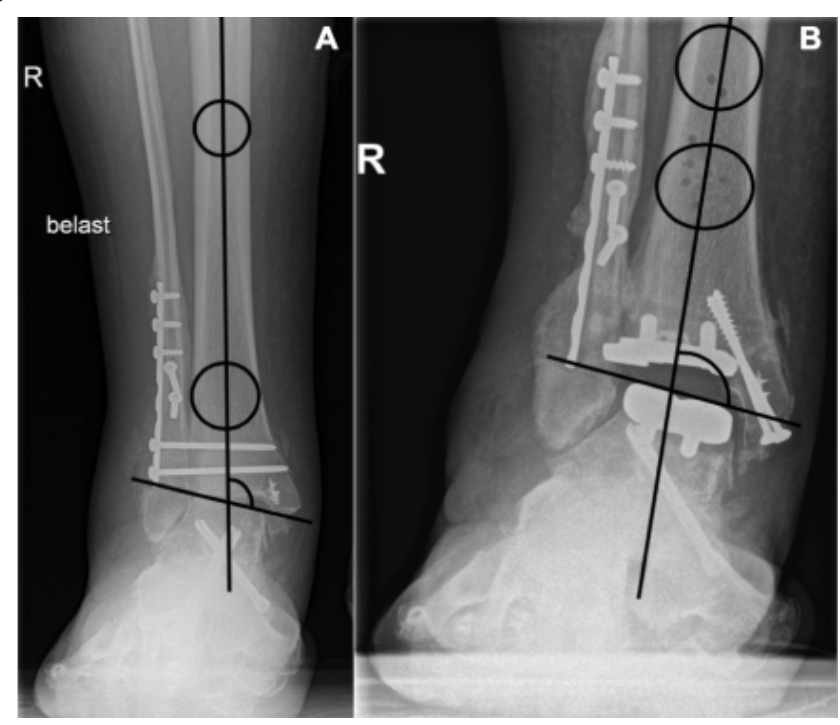

Figure 3: (A) Tibiotalar alignment measured with the angle between the mechanical axis of the tibia and a line tangential to the talar dome in pre-operative setting and; (B) The talar component in postoperative setting.

view. Tibial coronal alignment was determined with the medial distal tibial angle (MDTA) and tibial sagittal alignment was determined on the lateral radiograph with the anterior distal tibial angle (ADTA) (Figure 2). The ideal MDTA and ADTA is $90^{\circ}$ with a range of $5^{\circ}$ [13]. Tibiotalar alignment was determined as the angle between the mechanical axis of the tibia and a line tangential to the talar dome or talar prosthesis component (Figure 3 ). The ideal angle is $90^{\circ}$ with a range of $5^{\circ}$ [23]. The talar alignment was determined as the anteroposterior position of the talus in relation to the longitudinal axis of the tibia (Figure 4). When distance $x$ was positive the talus is positioned anteriorly, when distance $\mathrm{x}$ was negative the talus is positioned posteriorly [20].

Data was analysed using SPSS version 26.0 (released 2019. Armonk, NY: IBM). Continuous data are presented as means with standard deviations (SD) or as medians with interquartile and categorical data as frequencies with accompanying proportions. The Wilcoxon Singed Ranks tests were used to compare pre- and postoperative outcomes. Results were considered significant if $p<0.5$.

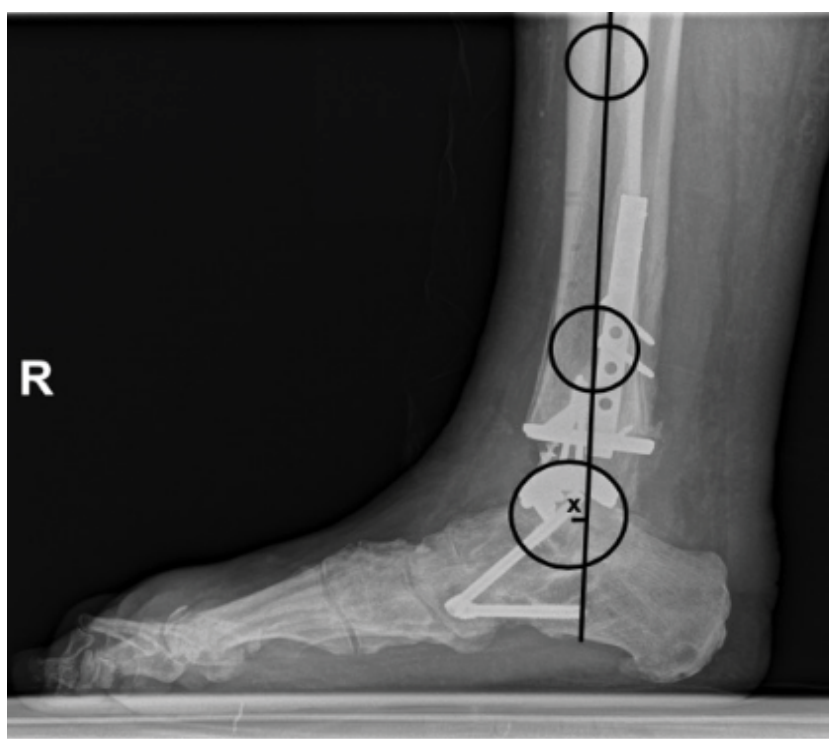

Figure 4: Anteroposterior position of the talus determined with distance $\mathrm{x}$, the distance between the centre of a circle on the talus component in relation to the longitudinal axis of the tibia.

Table 2: Surgery data.

Additional procedures during TAR surgery, n (\%)

Open reposition and internal fixation (ORIF)

$5(45.5)$

Achilles tendon lengthening

$5(45.5)$

Preventive k-wire fixation malleoli $3(27.3)$

Reoperation other than revision, $\mathbf{n}(\%)$

Dwyer osteotomy

Removal osteosynthesis material

Anterior tibia osteotomy

ORIF revision

Revision surgery, $\mathrm{n}(\%)$

$0(0.0)$

\section{Results}

During TAR surgery nine patients had 13 additional procedures, most commonly percutaneous Achilles tendon lengthening and osteosynthesis for intraoperative malleolar fractures (Table 2). All patients were discharged one or two days postoperatively. Five patients underwent a total of seven reoperations other than revision (Table 2).

Nine intraoperative complications occurred in seven patients (63.6\%). Six patients had a total of seven intraoperative fractures (Table 3). Five medial malleolar fractures were treated with internal fixation (ORIF) during TAR surgery (Table 2) and three patients had prolonged cast therapy. Two patients had an intraoperative injury of the superficial peroneal nerve (Table 3). One patient recovered completely.

Five patients (45.5\%) suffered eight short-term postoperative complications (Table 3). In three cases a superficial wound infection occurred which was treated with oral antibiotic treatment with good results in all 
cases. HO occurred in five cases, all located anteriorly (Figure 5).

The first days there was mild postoperative pain (Table 4). Preoperative ROM ranged from $5^{\circ}$ to $50^{\circ}$ with a mean of $26.7 \pm 3.4$ and ranged postoperatively from $10^{\circ}$ to $35^{\circ}$ with a mean of $22.5 \pm 7.6$. The total ROM and clin-

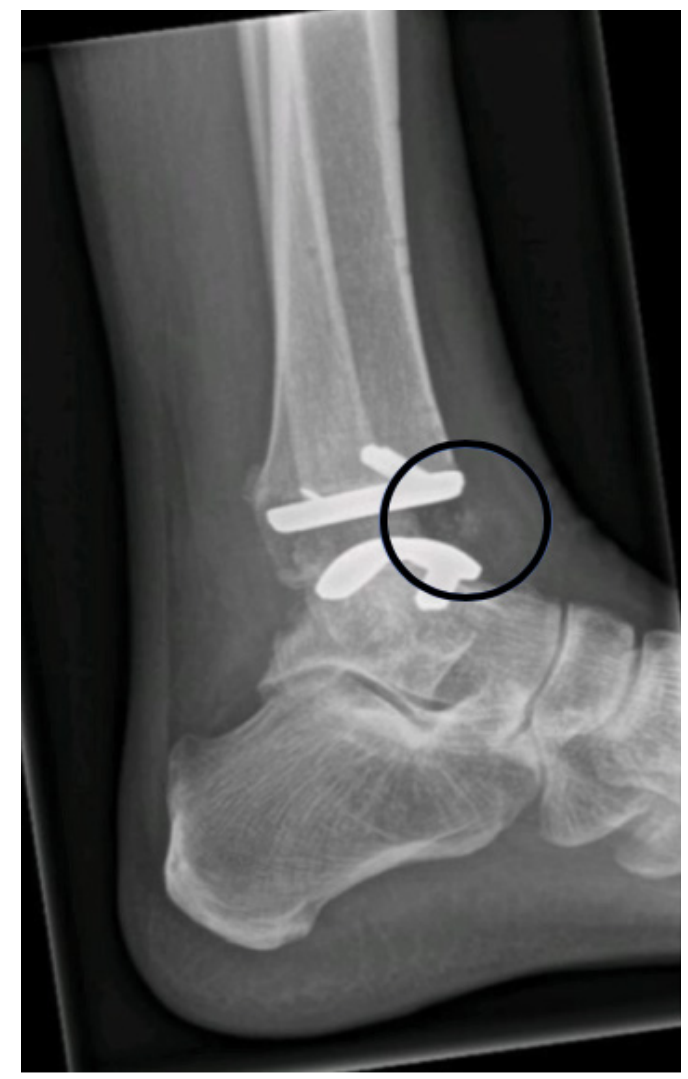

Figure 5: Heterotopic ossification $(\mathrm{HO})$ in the anterior gutter in one of the patients. ical ankle alignment did not change (Table 4). Preoperatively valgus malalignment was most common.

Six patients (54.5\%) stated to be satisfied, four patients (36.4\%) were moderately satisfied with their TAR despite their complications (Table 3 ). Two patients noticed a clicking sound in their ankle. One patient (9.1\%) stated to be unsatisfied due to difficulties walking longer distances.

The preoperative MDTA ranged from $83.8^{\circ}$ to $100.3^{\circ}$ with nine ankles in the normal range between $85^{\circ}$ and $95^{\circ}$. One ankle had a varus malalignment of $1.1^{\circ}$ and one ankle had a valgus malalignment of $5.3^{\circ}$. Postoperatively the MDTA ranged from $82.9^{\circ}$ to $96.5^{\circ}$ with nine ankles in the normal range. The preoperative varus and valgus

Table 3: Intraoperative and short-term postoperative complications.

\begin{tabular}{|l|l|}
\hline Intraoperative complications & \\
\hline Medial malleolar fracture, $\mathrm{n}(\%)$ & $6(54.5)$ \\
\hline Lateral malleolar fracture, $\mathrm{n}(\%)$ & $0(0.0)$ \\
\hline Tibial fracture, $\mathrm{n}(\%)$ & $1(9.1)$ \\
\hline Nerve injury, $\mathrm{n}(\%)$ & $2(18.2)$ \\
\hline Tendon laceration, $\mathrm{n}(\%)$ & 0 \\
\hline Total & $\mathbf{9}(\mathbf{8 1 . 8 )}$ \\
\hline Short-term postoperative complications & \\
\hline Delayed wound healing, $\mathrm{n}(\%)$ & $0(0.0)$ \\
\hline Superficial infection, $\mathrm{n}(\%)$ & $3(27.3)$ \\
\hline Deep infection, $\mathrm{n}(\%)$ & $0(0.0)$ \\
\hline Thromboembolism, $\mathrm{n}(\%)$ & $0(0.0)$ \\
\hline Heterotopic ossification, $\mathrm{n}(\%)$ & $5(45.5)$ \\
\hline Total & $\mathbf{8}(\mathbf{7 2 . 7 )}$ \\
\hline
\end{tabular}

Table 4: Clinical outcomes.

\begin{tabular}{|l|l|l|l|}
\hline & First day after surgery & Day of discharge & P-value \\
\hline NRS pain score, mean (SD) & $2.7(1.0)$ & $2.5(0.8)$ & 0.23 \\
\hline Range of motion (degrees), mean (SD) & Preoperative & $\mathbf{3 - 6}$ months postoperative & P-value \\
\hline Dorsal flexion & $2.6(3.4)$ & $2.5(4.6)$ & 0.71 \\
\hline Plantar flexion & $24.1(11.1)$ & $20.0(4.6)$ & 0.19 \\
\hline Overall ROM & $26.7(11.9)$ & $22.5(7.6)$ & 0.28 \\
\hline Ankle alignment, $\mathbf{n}(\%)$ & & & 0.08 \\
\hline Neutral & $2(18.2)$ & $5(45.5)$ & 1.00 \\
\hline Varus & $3(27.3)$ & $2(18.2)$ & 0.08 \\
\hline Valgus & $6(54.5)$ & $2(18.2)$ & $2(18.2)$ \\
\hline Not reported & $0(0.0)$ & & \\
\hline
\end{tabular}

Table 5: Radiological outcomes.

\begin{tabular}{|l|l|l|l|}
\hline & Preoperative & Postoperative & p-value \\
\hline Tibial alignment, MDTA; mean(SD) & $89.8(4.2)$ & $89.2(3.4)$ & 0.42 \\
\hline Tibial alignment, ADTA; mean (SD) & $92.9(7.9)$ & $90.5(7.2)$ & 0.21 \\
\hline Tibiotalar alignment, mean (SD) & $85.1(9.6)$ & $90.1(7.0)$ & 0.11 \\
\hline Talar alignment, mean (SD) & $6.5(3.7)$ & $7.3(3.6)$ & 0.40 \\
\hline
\end{tabular}


deformity were corrected to normal range. Two ankles gained a postoperative deformity, one varus malalignment of $2.1^{\circ}$ and one valgus malalignment of $1.5^{\circ}$.

The ADTA ranged preoperatively from $81.1^{\circ}$ to $105.2^{\circ}$ with three ankles in the normal range between $85^{\circ}$ and $95^{\circ}$. The mean deformity in the other eight patients was $3.8^{\circ} \pm 2.8^{\circ}$. Postoperatively the ADTA ranged from $82.9^{\circ}$ to $96.5^{\circ}$ with five ankles in the normal range. The mean deformity in the other six patients was $3.5^{\circ} \pm 2.3^{\circ}$. There was no significant difference in preoperative and postoperative MDTA and ADTA (Table 5).

Preoperatively the tibiotalar alignment ranged from $68.5^{\circ}$ to $100.2^{\circ}$ with four ankles in the normal range between $85^{\circ}$ and $95^{\circ}$. Five ankles had a varus deformity with a mean of $7.6^{\circ} \pm 7.3^{\circ}$ and two ankles had a valgus deformity of $0.6^{\circ}$ and $5.2^{\circ}$ degrees. The postoperative tibiotalar alignment ranged from $81.5^{\circ}$ to $106.2^{\circ}$ with seven ankles in the normal range. Two ankles had a valgus malalignment of $4.1^{\circ}$ and $11.2^{\circ}$, and two ankles had a varus malalignment of $0.7^{\circ}$ and $3.5^{\circ}$.

The mean preoperative talar alignment ranged between $0.9 \mathrm{~mm}$ to $12.8 \mathrm{~mm}$ and was translated anteriorly in all cases. The mean postoperative talar alignment ranged from $0.8 \mathrm{~mm}$ to $15.1 \mathrm{~mm}$ and was translated anteriorly in all cases. There was no significant difference in preoperative and postoperative tibiotalar and talar alignment (Table 5).

\section{Discussion}

This study evaluated the short-term outcomes of the Cadence total ankle prosthesis in terms of complications, clinical outcomes and radiological outcomes.

In total nine intraoperative complications $(81.8 \%)$ occurred in seven patients and eight postoperative complications (72.7\%) occurred in five patients. Compared to the available evidence this is a high complication rate. Reported overall complication rates for TAR are between $14.3 \%$ and $40 \%[2,9,10,12,14,16,19,23]$, with reported intraoperative complication rates between $3 \%$ and $16 \%$ and postoperative complication rates between $13.5 \%$ and $19 \%[1,3,11,13,20,24,25]$. Despite the high complication rates in this study most patients were satisfied with their ankle replacement. Most complications had no lasting effect, one patient had permanent nerve injury.

With the first patients, and in a small cohort, introducing a new prosthesis could lead to higher complication rates because of the surgeons learning curve with the new prosthesis design [9-11]. In a similar patient group, Nery, et al. reported 10 complications in 8 patients in a case series with their first 10 HINTEGRA TAR's [26]. Lee, et al. reported a complication rate of $60 \%$ in their first 25 cases which decreased to $20 \%$ in the following 25 cases [9].

Further, heterogeneity in complication reported makes it hard to compare complication rates. Complications are categorized as intraoperative and postoperative $[1,3,11,13,20,25]$, as minor and major $[18,19,26]$, as high grade, medium grade, and low grade $[2,10,23]$, or are not classified at all $[2,9,12,14,16]$. A further issue is heterogeneity in which events are counted as complications, for example $\mathrm{HO}$ is sometimes mentioned as complication and sometimes as radiological outcome. It is also important to note that survival data is influenced by surgeon designer studies [3]. This could also affect complication rates. Likewise, database studies could have lower complication rates since only complications wherefore surgical intervention is needed are registered.

In this case series there was a high rate of reoperations other than revision (63.6\%). This could be caused by the removal of osteosynthesis material in $50 \%$ of the medial malleolar fractures. In literature reoperation procedures vary between $2.9 \%$ and $26 \%$ $[1,2,9,10,13,14,20,23-25]$. In this study there were no revisions, which varies between $2.1 \%$ and $22.0 \%$ in other studies $[1,10,11,13,14,20,23-25]$. However, the follow-up of the current study was rather short.

Clinical evaluation showed no significant difference in pain score between the first postoperative day and the day of discharge. It should be noted that some patients were discharged on the first postoperative day. We had no preoperative pain scores to compare to and, due to the short-term follow-up in this study, no long-term pain scores. It has been shown that TAR significantly decreases pain scores on the long term $[3,16,18,20,25,26]$.

There was no significant difference in ROM as opposed to other studies $[3,19,20,25,26]$. There even was a decrease in postoperative plantar flexion, although not significantly, which could be caused by an outlier score in the preoperative clinical measurement of $50^{\circ}$. Further, triple arthrodesis could affect postoperative ROM. Kim, et al. found in their study no significant difference in ROM after TAR in combination with hindfoot arthrodesis [8]. Since the majority of patients in this study underwent triple arthrodesis, this could possibly affect postoperative ROM.

The mean postoperative MDTA of $89.2^{\circ}$ found in this study is comparable to other studies $[9,10,15,20,24]$. The mean ADTA was $90.5^{\circ}$ with a mean deformity of $3.5^{\circ}$ in six ankles. Literature is conflicting on the ideal ADTA. Some studies report an ideal angle of $90^{\circ}[10,13,15]$ and other studies report an ideal angle of $85^{\circ}[2,9,20]$. The mean postoperative tibiotalar angle of $90.1^{\circ}$ is comparable to other studies, with a reported mean angle of $88.5^{\circ}$ and mean deformity of $1.6^{\circ}$ and $3^{\circ}[2,10,23]$. The mean talar alignment of $7.3 \mathrm{~mm}$ was in all cases translated anteriorly, which was also found by Choi, et al. and Mann, et al. $[2,20]$. Mangegold, et al. and Barg, et al. found a more equal distribution in talar alignment, with normal and posterior translations as well $[15,27]$. 
It should be noted that not all radiographs in this study were weight bearing. Non-weight bearing radiographs could influence radiological alignment. Another factor complicating comparison of the results to other studies is the wide variety in alignment measurements and how they are reported (as mean angle, as mean deformity, or as mean varus deformity).

This study has several limitations. Firstly, it is a retrospective study. This means not all data was complete, there were no patient reported outcome measurements (PROMs) available as clinical outcome, there was no preoperative pain score and not all patients had weight bearing radiographs. Secondly, the surgeon learning curve that could be associated with a new prosthesis is of high impact in a small patient group. Another limitation is the short-term follow-up since we focused on intraoperative and short-term postoperative complications, which made it impossible to evaluate some important long-term complications such as cyst formation and radiolucency.

\section{Conclusion}

The short-term results of our first eleven Cadence total ankle prostheses showed a high complication rate. More research on this new prosthesis is necessary. Clinical outcomes are encouraging and show low postoperative pain scores, a preservation of ROM, and a good clinical alignment. Radiological alignment was in most cases within normal range. Most importantly, most patients were satisfied with their new ankle.

We believe this case series with the results of our first patients with the Cadence total ankle prosthesis is important as they are the first result of this new prosthesis and they are outcomes by non-designers. These outcomes are important for other surgeons to learn from and to compare their own outcomes too.

\section{Acknowledgements}

The authors want to thank Marjolein Schager for providing language help.

\section{Declaration of Conflicting Interests}

The authors declare that there is no conflict of interest.

\section{References}

1. Kerkhoff YRA, Kosse NM, Metsaars WP, Louwerens JWK (2016) Long-term functional and radiographic outcome of a mobile bearing ankle prosthesis. Foot Ankle Int 37: 12921302.

2. Mann JA, Mann RA, Horton E (2011) STAR ${ }^{T M}$ ankle: Longterm results. Foot Ankle Int 32: S473-S484.

3. Zaidi R, Cro S, Gurusamy K, Siva N, Macgregor A, et al. (2013) The outcome of total ankle replacement: A systematic review and meta-analysis. Bone Joint J 95: 1500-1507.

4. Syed F, Ugwuoke A (2018) Ankle arthroplasty: A review and summary of results from joint registries and recent studies. EFORT Open Rev 3: 391-397.
5. Gougoulias NE, Khanna A, Maffulli N (2009) History and evolution in total ankle arthroplasty. Br Med Bull 89: 111151.

6. van den Heuvel A, Van Bouwel S, Dereymaeker G (2010) Total ankle replacement. Design evolution and results. Acta Orthop Belg 76: 150-161.

7. Doets HC, van der Plaat LW, Klein JP (2008) Medial malleolar osteotomy for the correction of varus deformity during total ankle arthroplasty: Results in 15 ankles. Foot Ankle Int 29: 171-177.

8. Kim BS, Knupp M, Zwicky L, Lee JW, Hintermann B (2010) Total ankle replacement in association with hindfoot fusion: Outcome and complications. J Bone Joint Surg Br 92: 15401547.

9. Lee KB, Cho SG, Hur Cl, Yoon TR (2008) Perioperative complications of HINTEGRA total ankle replacement: Our initial 50 cases. Foot Ankle Int 29: 978-984.

10. Pangrazzi GJ, Baker EA, Shaheen PJ, Okeagu CN, Fortin PT (2018) Single-surgeon experience and complications of a fixed-bearing total ankle arthroplasty. Foot Ankle Int 39: 46-58.

11. Schimmel JJP, Walschot LHB, Louwerens JWK (2014) Comparison of the short-term results of the first and last 50 Scandinavian total ankle replacements: Assessment of the learning curve in a consecutive series. Foot Ankle Int 35: 326-333.

12. Clement RC, Krynetskiy E, Parekh SG (2013) The total ankle arthroplasty learning curve with third-generation implants: A single surgeon's experience. Foot Ankle Spec 6: 263-270.

13. Kerkhoff YRA, Kosse NM, Louwerens JWK (2016) Short term results of the mobility total ankle system: Clinical and radiographic outcome. Foot Ankle Surg 22: 152-157.

14. Karantana A, Hobson S, Dhar S (2010) The scandinavian total ankle replacement: Survivorship at 5 and 8 years comparable to other series. Clin Orthop Relat Res 468: 951-957.

15. Mangegold S, Springer A, Landvoigt K, Tsitsilonis S (2017) Heterotopic ossification after total ankle replacement: The role of prosthesis alignment. Foot Ankle Surg 23: 122-127.

16. Chao J, Choi JH, Grear BJ, Tenenbaum S, Bariteau JT, et al. (2015) Early radiographic and clinical results of Salto total ankle arthroplasty as a fixed-bearing device. Foot Ankle Surg 21: 91-96.

17. Clough TM, Alvi F, Majeed H (2018) Total ankle arthroplasty: What are the risks?: A guide to surgical consent and a review of the literature. Bone Joint J 100: 1352-1358.

18. Brigido SA, Galli MM, Bleazey ST, Protzman NM (2014) Modular stem fixed-bearing total ankle replacement: Prospective results of 23 consecutive cases with 3-year follow-up. J Foot Ankle Surg 53: 692-699.

19. Rodrigues-Pinto $R$, Muras $J$, Martin Oliva $X$, Amado $P$ (2013) Functional results and complication analysis after total ankle replacement: Early to medium-term results from a Portuguese and Spanish prospective multicentric study. Foot Ankle Surg 19: 222-228.

20. Choi GW, Kim HJ, Yeo ED, Song SY (2013) Comparison of the HINTEGRA and Mobility total ankle replacements. Short- to intermediate-term outcomes. Bone Joint J 95: 1075-1082.

21. BioSpace (2016) Integra Lifesciences announces first clinical uses of Cadence Total Ankle System in Europe.

22. Integra. Cadence Total Ankle system. Surgical technique. 
23. Saito GH, Sanders AE, de Cesar Netto C, O'Malley MJ, Ellis SJ, et al. (2018) Short-term complications, reoperations, and radiographic outcomes of a new fixed-bearing total ankle arthroplasty. Foot Ankle Int 39: 787-794.

24. Najefi A, Malhotra K, Chan O, Cullen N, Goldberg A (2019) The Bologna-Oxford ankle replacement: A case series of clinical and radiological outcomes. Int Orthop 43: 23332339.

25. Rippstein PF, Huber M, Coetzee JC, Naal FD (2011) Total ankle replacement with use of a new three-component implant. J Bone Joint Surg Am 93: 1426-1435.
26. Nery C, Fernandes TD, Ressio C, Fuchs ML, Godoy Santos AL, et al. (2010) Total ankle arthroplasty: Brazilian experience with the HINTEGRA prosthesis. Rev Bras Ortop 45: 92-100.

27. Barg A, Elsner A, Anderson AE, Hintermann B (2011) The effect of three-component total ankle replacement malalignment on clinical outcome: Pain relief and functional outcome in 317 consecutive patients. J Bone Joint Surg Am 93: 1969-1978. 